\title{
Leadership and leadership development in healthcare settings - a simplistic solution to complex problems?
}

\author{
Ruth McDonald*
}

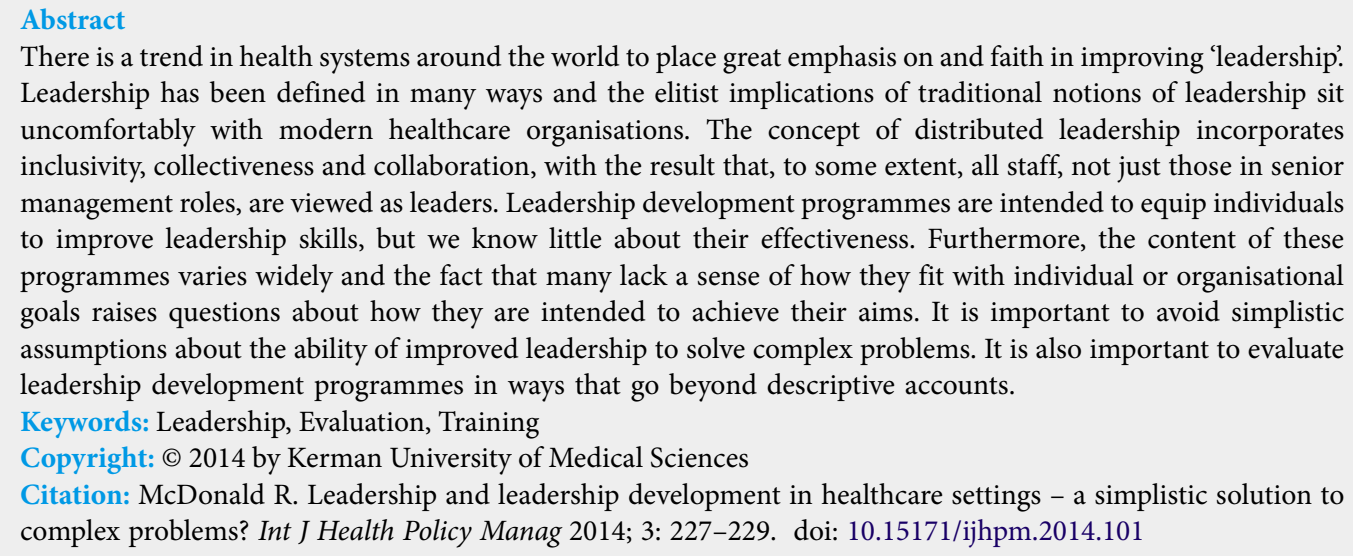

There is a trend in health systems around the world to place great emphasis on and faith in improving 'leadership'. Leadership has been defined in many ways and the elitist implications of traditional notions of leadership sit uncomfortably with modern healthcare organisations. The concept of distributed leadership incorporates inclusivity, collectiveness and collaboration, with the result that, to some extent, all staff, not just those in senior management roles, are viewed as leaders. Leadership development programmes are intended to equip individuals to improve leadership skills, but we know little about their effectiveness. Furthermore, the content of these programmes varies widely and the fact that many lack a sense of how they fit with individual or organisational goals raises questions about how they are intended to achieve their aims. It is important to avoid simplistic assumptions about the ability of improved leadership to solve complex problems. It is also important to evaluate leadership development programmes in ways that go beyond descriptive accounts.

Keywords: Leadership, Evaluation, Training

Copyright: @ 2014 by Kerman University of Medical Sciences

Citation: McDonald R. Leadership and leadership development in healthcare settings - a simplistic solution to complex problems? Int J Health Policy Manag 2014; 3: 227-229. doi: 10.15171/ijhpm.2014.101

Article History:

Received: 30 September 2014 Accepted: 14 October 2014 ePublished: 14 October 2014
$\mathrm{S}$ urveying the health policy landscape in my own country and beyond, I am often reminded of HL Menken's dictum that 'there is always a solution to every human problem: neat, plausible and wrong' (1). One such 'solution' appears to be leadership. Calls for more and better leadership abound (2), with leadership being viewed as the answer to various complex problems in healthcare settings. In the context of the English National Health Service (NHS), the Leadership Academy has recently celebrated its second anniversary. It is owned by the NHS and offers a range of programmes intended to broaden the range of leadership behaviours people use, as well as professionalising leadership, making leadership more inclusive and representative of the communities it serves and developing leaders who embrace and facilitate innovation.

The Academy's website proclaims that there is 'unequivocal evidence in every sector that there is a strong relationship between leadership capability and performance' (3). Yet the evidence presented is scant and somewhat selective. These claims contrast with a recent review which found that "although there are many publications stressing the importance ofleadership....only a few studies provide observational evidence to support this view, and no studies have rigorously tested this proposition in health care" (4). Furthermore, leadership appears to be defined in different ways in the evidence presented. Studies which focus on CEO performance, suggest a rather narrow view of leadership, for example.

The emphasis on leadership may oversimplify the complexity of problems in healthcare settings. It also ignores the 'dark side' of leadership. In times of crisis, we are drawn towards leaders with extreme views, who appear to offer certainty, but do so by ignoring nuance and complexity (5). Our judgments about the 'honourable' or otherwise status of individuals can be flawed, leading us to mistakenly attribute legitimate competence to particular kinds of people and see them as worthy of leadership positions (6).

It is not just the behaviour of 'followers' that matters, but the behaviour of leaders is also important. There is a wealth of evidence which demonstrates how people in positions of power are more likely to engage in hypocrisy, as well as having a sense of entitlement which they feel excuses them from having to comply with the rules which govern subordinates. Power can have an effect on the mindset of those who possess it (7). It has been shown to reduce some individuals' ability to estimate the interests and positions of others and see things from other people's point of view. This also means that they may expect others to interpret things in the same way as they do. Possession of power can also increase the use of crude stereotypes, as well as risk taking behaviour (8). Powerful individuals are more likely than others to exhibit and report confidence in their own judgment. This means that they may fail to notice important information from external sources and they are less likely to take advice compared with less powerful individuals. This can create a situation in which the most powerful people in the organisation can be the least accurate in terms of their judgments (8).

Coupled with the potential negative consequences of power, the elitist implications of traditional notions of leadership sit uncomfortably with modern healthcare organisations, where it seems that nowadays, leadership is everybody's business. The concept of distributed leadership has been defined 
in many ways, but these various definitions incorporate inclusivity, collectiveness and collaboration. It is seen as the sort of leadership suited to the complex and interdependent nature of healthcare where there is a need for leadership to take on a more distributed and collective style, due to the existence of professional jurisdictions, which limit formal authority. Leadership is assumed to apply to a wide group of stakeholders, with the result that, to some extent, all staff, not just those in senior management roles, are viewed as leaders. As some have noted, in England there has been a shift away from 'management' towards 'leadership' in NHS policy documents and discourse more generally. The latter has come to be seen as more interesting and exciting than the former (9). At the same time, critical scholars point to the potential for leadership discourse and practice to influence the subjectivities of individuals, 'governing at a distance'. Similarly, Martin and Learmonth add their voice to an increasingly critical perspective on leadership describing it as 'a fig leaf to hide the more oppressive aspects of life in healthcare provision' (10). The argument here is that designating activities as 'leadership' is a means of inveigling employees into undertaking tasks which are onerous and beyond the call of duty. Describing something as a heavy and burdensome administrative role sounds much less attractive. But leadership, like motherhood and apple pie is hard to resist.

If leadership really is everybody's business then how are employees to develop into full participants in distributed leadership processes? There are many providers in the marketplace who are keen to offer leadership development programmes. The content of these programmes varies a great deal and some are tailored to specific groups [e.g. women, staff from Black and Minority Ethnic (BME) communities]. In general, we know little about the nature of training and development that staff need and we have little evidence on which to base investment decisions in this area. As far as possible, it appears sensible for leadership development programmes to be underpinned by theory, preferably theory which links action to desired outcomes. Yet this is not an easy task. Much progress has been made at fleshing out concepts such as 'servant leadership' and emotional intelligence, which have been identified by some as core components of well-constructed programmes (11). But more work is needed to understand how these are hypothesised to impact on performance. We know that leadership style impacts on organisational culture, which in turn impacts on performance. However, attempts to deliberately engineer and change culture suggest that this is a difficult task to say the least.

Seen through a sceptic's lens, there is a risk that leadership development in the NHS will be used as a means of controlling people, rather than encouraging them to develop their knowledge and skills. McDonald's (12) exploration of a leadership programme ostensibly aimed at 'empowering' NHS employees suggested that this was a mechanism intended to encourage cultivation of certain forms of 'ethical' selfhood. Participants were exhorted to accept constraints and high workloads as part of the process of becoming ostensibly empowered selves. In this way, what is presented as empowerment, is really a form of 'governing the soul' (13), with individuals being active participants in processes aimed at controlling them. Tomlinson et al. (14) are similarly critical of attempts at 'remote control' via leadership development programmes in the public sector. The authors, drawing on interviews with public sector personnel from health and education, note that access to elite development appealed to participants' interest in self-advancement and positional power. At the same time, high levels of consent and selfregulation meant that leaders did not engage in critique and resistance in the face of top down reforms. The authors suggest that all of this contributes to the enhancement of leaders' strongholds in a way which reproduces inequality and preserves power differentials.

How then are those who are not so well represented in the upper echelons of the organisation to behave if this is true? Should they resist attempts to recruit them into leadership programmes on the grounds that these are efforts to control them? Should they embrace such programmes as an opportunity for self-advancement? There are leadership programmes aimed specifically at members of BME communities, lesbian and gay people and women amongst others. More research examining such programmes would be helpful in understanding the content of the programmes and the theories underpinning them. For example, is the aim that programme participants will build a network of contacts from fellow participants? Will the emphasis be on authenticity or on blending in as part of a world where prejudice is common and 'rocking the boat' can be detrimental to career progression? And will time and space be given to tackling internalised oppression? Or is the programme constrained to focusing on the external barriers to leadership development for marginalised groups? Whilst there are calls for programmes dedicated to addressing marginalised groups and to paraphrase the Leadership Academy, making leaders more representative of the communities they serve, we know little about how to design such programmes to maximise their chances of success. Evidence (15) suggests that people eligible for such programmes may not apply due to a fear that they will be seen as second rate, which raises questions about whether dedicated programmes are preferable to more generic approaches.

It is not my intention to argue that we should view the various leadership development programmes offered by the NHS Leadership Academy as attempts at 'remote control'. Additionally, the absence of evidence linking leadership development to improved outcomes is not the same thing as evidence that such programmes are not effective. However, it is important that we do not accept 'leaderism' and leadership development uncritically. A recent review of leadership development programmes in health (16) notes that they often lack a theoretical base and a sense of how they fit with individual or organisational goals. Linked to this, evaluations of such programmes often lack a theoretical foundation and can be little more than limited descriptive accounts.

In this context, a recent call for studies to evaluate leadership development programmes summarises the issue. 'Although considerable resources have been spent on leadership development, we do not know if this is the right level of 
investment, targeted at the right people or whether it works in producing good leaders and improved care. These issues are hard to unpack' (17). The call is to be welcomed since it reminds us that we should not just assume that leadership development is a good thing. Furthermore, it emphasises the importance of theory driven approaches and stresses the desirability of evaluation rather than simple description. At the same time, such evaluation presents considerable challenge. It is to be hoped that some of these challenges can be overcome to provide robust evidence on which to draw meaningful conclusions about this important issue.

\section{Ethical issues}

Not applicable.

Competing interests

Author declares that she has no competing interests.

Author's contribution

$\mathrm{RM}$ is the single author of the manuscript.

\section{References}

1. Mencken HL. The Divine Afflatus. New York Evening Mail. 16 November 1917.

2. Storey J, Holti R. Possibilities and pitfalls for clinical leadership in improving service quality, innovation and productivity. Report for the National Institute for Health Research Service Delivery and Organisation programme. London: HMSO; 2013.

3. NHS Leadership Academy [homepage on the internet]. [cited 2014 September 30]. Available from: http://www. leadershipacademy.nhs.uk/about/

4. Ovretveit J. Leading Improvement Effectively: a review of research and guidance for leaders. Part 1: The Research. London, Stockholm: Health Foundation; 2009

5. Tourish D. The Dark Side of Transformational Leadership: A Critical Perspective. London: Routledge; 2013.

6. McDonald R. 'Bourdieu', medical elites and 'social class': a qualitative study of 'desert island' doctors. Sociol Health IIIn
2012; 36: 902-16. doi: 10.1111/1467-9566.12121

7. Keltner D, Gruenfeld D, Anderson C. Power, Approach, and Inhibition. Psychol Rev 2003; 110: 265-84. doi: 10.1037/0033295x.110.2.265

8. Seea KE, Morrisona EW, Rothmanb NB, Sollc JB. The detrimental effects of power on confidence, advice taking and accuracy. Organ Behav Hum Decis Process 2011; 16: 272-85. doi: $\quad$ 10.1016/j.obhdp.2011.07.006

9. Ford J, Harding $\mathrm{N}$. Move over management - We are all leaders now. Management Learning 2007; 38: 475-93. doi: 10.1177/1350507607083203

10. Martin GP, Learmonth MA. Critical account of the rise and spread of 'leadership': The case of the UK healthcare. Soc Sci Med 2012; 74: 281-8. doi: 10.1016/j.socscimed.2010.12.002

11. National Center for Health Leadership (NCHL). Best Practices in Healthcare Leadership Academies. 2010. Available from: http://www.nchl.org/Documents/Ctrl_Hyperlink/doccopy5381_ uid6102014456192.pdf

12. McDonald R. Individual identity and organisational control: Empowerment and Modernisation in a Primary Care Trust. Sociol Health IIIn 2004; 26: 925-50. doi: 10.1111/j.01419889.2004.00423.x

13. Rose N. Governing the Soul: The Shaping of the Private Self. London: Routledge; 1990.

14. Tomlinson M, O'Reilly D, Wallace M. Developing leaders as symbolic violence: Reproducing public service leadership through the (misrecognized) development of leaders' capitals. Management Learning 2103; 44: 81-97. doi: 10.1177/1350507612472151

15. McDonald R. A qualitative evaluation of the BME Leadership Development Programme for NHS Staff in 3 regions. A report commissioned by the East Midlands NHS Leadership Academy. Nottingham: University of Nottingham; 2013.

16. Hartley J, Bennington J. Leadership for Healthcare. Bristol: Policy Press; 2010.

17. National Institute for Health Research (NIHR). Commissioning Brief 14/155 - New research on leadership development in health and care. Southampton, UK. 